\title{
Introducing dynamic asphalt modulus to the design of flexible aircraft pavement structures
}

\author{
H. Weisser \& G. White \\ School of Science and Engineering, University of the Sunshine Coast, Sippy Downs, Queensland, Australia
}

\begin{abstract}
Most modern aircraft pavement thickness design methods are mechanisticempirical, with the mechanistic element based on layered-elastic analysis of trial pavement structures, which are refined until they are optimised for the subgrade conditions and project aircraft traffic loadings. An elastic modulus and Poisson's ratio are assigned to each layer in the pavement. In the past, presumptive or standard values of modulus have been used for the various pavement layers. This includes the granular crushed rock or natural gravel, as well as the asphalt surface and sub-surface asphalt layers. However, in modern times, there is great interest in using a mixture-specific dynamic asphalt modulus. As the traffic speed increases and the temperatures reduces, the asphalt modulus increases significantly. Because the temperature of asphalt changes with the depths of the layer within the pavement and with day-night and summer-winter fluctuations, dynamic modulus is complex and is not readily incorporated in layered-elastic software. This research measured the modulus of a typical dense graded airport asphalt mixture at various temperatures and load speeds and incorporated the resulting dynamic modulus into aircraft pavement thickness design using APSDS via asphalt sub-layering. It was concluded that the difference in modulus associated with summer and winter, or day and night, temperature profiles changed the predicted life of the pavement by orders of magnitude, suggesting that all significant pavement damage occurs on the hottest few days of the pavement's life. Although dynamic asphalt modulus was relatively efficiently incorporated into APSDS, its use in routine layered elastic design is unlikely to be justifiable and is it expected to introduce more challenges than it is likely to solve.
\end{abstract}

Keywords: Airport, Asphalt, Dynamic modulus, Thickness design

\section{INTRODUCTION}

Modern flexible aircraft pavements are generally designed using the mechanistic-empirical, layered elastic method (AAA 2017). A static load is applied to the pavement and the stresses and strains are calculated at critical points in the pavement using layered elastic theory. The maximum strains at the critical points are then related to the theoretical number of allowable repetitions of that load until failure is predicted, using empirically derived transform functions, also known as performance criteria or failure criteria (Huang 1993). The pavement is modelled as layers of homogenous and infinitely wide elastic materials which are characterised by an elastic modulus and a Poisson's ratio (Huang 1993). The modulus values have a great impact on pavement thickness and for routine design, modulus values are usually sourced from literature or jurisdiction-based design guidance. The modulus assigned to the asphalt is 
generally constant or static. However, it is well established and broadly known that the modulus of asphalt depends on the temperature and load frequency imposed on it (Mounier et al. 2015).

The exact modulus of asphalt at a certain temperature and loading speed is known as the dynamic modulus and can be determined by laboratory testing. This includes testing over a range of load frequencies and temperatures, then creating a master curve of modulus (Mounier et al. 2015). It is expected that using dynamic modulus for a pavement design provides a more accurate pavement design as different climates that effect the prevailing modulus values are considered. Furthermore, it is clear that asphalt modulus is material specific, even for the same asphalt type. For example, polymer modified bitumen (PMB) is associated with higher or lower modulus values than otherwise comparable asphalt, depending on the polymer used (White \& Embleton 2015). Furthermore, different aggregate sources provide different contributions to mixture stiffness, depending on their shape, interparticle friction and affinity for bituminous binder (Pan et al. 2005). The use of a mixture-specific dynamic modulus allows these differences in asphalt mixtures to be accounted for in pavement design.

The aim of this research was to compare the standard design approach to a design based on dynamic asphalt modulus values. The modulus values were determined based on realistic pavement temperature profiles and the dynamic modulus characterisation of a typical aircraft pavement asphalt mixture. Different aircraft and a typical range of subgrade conditions were considered, allowing general trends to be explored across various practical design scenarios.

\section{BACKGROUND}

\subsection{Flexible aircraft pavements}

Similar to road pavement, flexible aircraft pavements consist of four primary courses, the asphalt surface, a base, subbase and the supporting subgrade. The asphalt surface layer generally consists of a hot mix asphalt produced with crushed and graded hard rock aggregate and natural sand (FAA 2016). There are often two asphalt layers, the wearing, or surface layer, and the supporting upper base layer, which transmits the load to the underlying granular layers. The wearing layer is usually made up of hard aggregate which can resist the high shearing forces associated with aircraft take-off and braking. The wearing layer also provides an impermeable surface, which prevents water from penetrating into the base layers. Base layers can be the same as the surface layer but commonly have a larger aggregate size and lower binder content, to increase the stiffness of the base.

Generally, airport pavements in Australia have a relatively thin asphalt surface, usually 50$100 \mathrm{~mm}$, over a layer a high quality and well compacted crushed rock base course (AAA 2017). In contrast, aircraft pavements in the USA usually have thicker asphalt surfaces and a bound upper base course. The upper base course is often asphalt, resulting in a total of approximately $250 \mathrm{~mm}$ of asphalt. Almost opposite to Australia, some European countries prefer only a thin lower subbase to act as a working platform, with the majority of the pavement built using high modulus asphalt layers (White et al. 2020). These full depth asphalt pavements are generally thinner, but more expensive to construct, than other pavements of equivalent structural strength. Despite these differences in the composition of aircraft pavements, the thickness is universally determined to protect the subgrade from the loadings associated with the projected aircraft traffic.

\subsection{Aircraft pavement thickness design}

As stated above, the layered elastic method is a mechanistic-empirical approach to design and is the most commonly used method for modern flexible pavement design. It uses a cumulative damage factor $(\mathrm{CDF})$, which is the ratio of the applied load repetitions compared to the 
allowable load repetitions that are predicted to cause the pavement to fail. Failure is generally defined in terms of asphalt fatigue cracking and/or permanent vertical subgrade deformation, commonly known as pavement rutting. A CDF below one means that the pavement has not yet reached its structural limit. Once the CDF reaches 1.0, the pavement is predicted to have failed (Mincad 2010).

Several layered elastic based pavement design softwares have been developed by different jurisdictions. The Federal Aviation Administration (FAA) has developed FAARFIELD (FAA 2017) which is commonly used in the USA and many other countries around the world. In France the software Alize is used (Balay et al. 2009), while in Australia, Airport Pavement Structural Design Software (APSDS) (Wardle \& Rodway 1998) is common. APSDS is similar to its parent software for road pavement design, known as Circly (Wardle 1977). Despite differences in user interfaces, flexibility, conservatism and some internal calculation processes, all these softwares are based on the same principles:

- The pavement layers and materials are selected.

- The layer thickness, material modulus and Poisson's ratio are assigned to each layer.

- A subgrade is selected for each pavement profile, characterised by a CBR and converted to an elastic modulus.

- Aircraft traffic spectra are defined by nominating one of more aircraft types, weights, tyre pressures and the number of load repetitions of each.

- The damage indicators, usually stress or strain, are calculated at the critical points.

- The maximum value of the critical damage indicator is converted to the number of allowable load repetitions using the applicable transform function.

- Using the CDF concept, the sum of the damage over all loads is calculated.

- The pavement thickness is iteratively increased or decreased until the CDF is equal to 1.0.

APSDS was chosen for this research as it is widely used in Australia and provides more flexibility for material inputs, such as modulus and layer thickness, compared to FAARFIELD. This makes APSDS particularly useful for pavement thickness determination of nonstandard materials and non-routine pavement structures (White et al. 2020).

\subsection{Pavement layer modulus}

As discussed above, APSDS allows for the modification of all the required pavement design input parameters. Most variables can be chosen from the APSDS internal library (Mincad 2010). This include the subgrade, which usually has a modulus equivalent to ten times the $\mathrm{CBR}$, and the base and subbase, which use automated sub layering known as the Barker and Brabston method (Barker \& Brabston 1975).

The asphalt modulus has traditionally been based on published static values for base $(3,300$ $\mathrm{MPa})$ and surface (1,500 $\mathrm{MPa}$ ) layers, which reflects the different temperature and its effect on asphalt modulus. The surface layer is exposed to the sunshine and solar radiation, increasing its temperature beyond that of the air. In contrast, sub-surface layers are insulated and their temperature changes are much lower, with asphalt more than $300 \mathrm{~mm}$ below the pavement surface generally considered to experience a constant temperature state (Gray et al. 2015). The traditional static or constant asphalt modulus values are expected to represent asphalt produced with unmodified binders, during a typical summer day in most temperate climates. However, road pavement design has introduced material, vehicle speed and temperature specific modulus values, generally known as the dynamic modulus. This approach has been adopted for this research.

\subsection{Dynamic modulus of asphalt}

The dynamic modulus can be determined via different laboratory tests, such as the flexural and compressive methods detailed in Austroads AGPT-T274-16 and the American Association of State Highway and Transportation Officials (AASHTO) T 342-11 respectively. These 
tests measure the modulus at several temperature and frequency combinations. Using these results, master curves can be constructed and fitted to best match the test results, as detailed in the Queensland Department of Transport and Main Roads (TMR) Technical Note 167. The master curves depend on the reduced frequency, a temperature shift factor $\left(\alpha_{t}\right)$ and several master curve fitting parameters $\left(\mathrm{C}_{1}, \mathrm{C}_{2}, \alpha, \beta, \gamma\right.$ and $\left.\delta\right)$ (Equation 1). The temperature shift factor can be calculated using several methods. The Williams-Landel-Ferry Equation (WLF Equation) was chosen for this research, as it was found to be the most accurate option for asphalt materials (Equation 3).

$$
E_{\text {pred }}=10^{\delta+\frac{\alpha}{1+e^{\beta+\gamma * \log _{\text {red }}}}}
$$

Where: $\mathrm{E}_{\text {pred }}=$ Predicted modulus $(\mathrm{MPa})$.

$\alpha, \beta, \gamma$ and $\delta=$ master curve fitting parameters.

$\mathrm{f}_{\text {red }}=$ reduced frequency as per (Equation 2$)$.

$$
f_{\text {red }}=\alpha_{t} * f
$$

Where: $\alpha_{t}=$ temperature shift factor as per (Equation 3).

$\mathrm{f}=$ frequency $(\mathrm{Hz})$.

$$
\log \alpha_{t}=\frac{-C_{1}\left(T-T_{r e f}\right)}{C_{2}+\left(T-T_{r e f}\right)}
$$

Where: $\alpha_{\mathrm{t}}=$ temperature shift factor.

$\mathrm{C} 1$ and $\mathrm{C} 2=$ empirical constants.

$\mathrm{T}=$ temperature at testing $\left({ }^{\circ} \mathrm{C}\right)$.

$\mathrm{T}_{\text {ref }}=$ temperature of interest $\left({ }^{\circ} \mathrm{C}\right)$.

Although Equation 3 is convenient, it applies only to a single temperature value. Because the temperature of the pavement varies with depth, a new version of Equation 3 must be used for each depth of interest, based on the estimated temperature at that depth. Accordingly, the usefulness of the predicted modulus is dependent on the accuracy of the temperature profile used to determine the pavements temperature at different depths.

\subsection{Temperature profiles}

The temperature of the asphalt is critically important to implementing dynamic modulus implementation and can either be measured or predicted. The temperature of asphalt depends on several factors including the depth of the measurement, the daily temperature and the solar radiation (Gray et al. 2015). This makes temperature predictions complex and several temperature models are available to predict the temperature of asphalt at different depths and in different locations.

Gedafa et al. (2014) developed and validated a model that predicts the temperature in asphalt pavements. They found a linear relationship between the temperature in the middle of each pavement layer $\left(\mathrm{T}_{\text {pavt }}\right)$ at a certain depth $(\mathrm{D})$ and the pavements surface temperature $\left(\mathrm{T}_{\text {sur }}\right)$, as well as the average air temperature of the previous day $\left(\mathrm{T}_{\text {sur }}\right)$ and the time of day $\left(\mathrm{t}_{\mathrm{d}}\right)$ at which the temperature has been measured. The model (Equation 4) had a coefficient of determination $\left(\mathrm{R}^{2}\right)$ of 0.94 when correlated to the measured temperatures, indicating a high level of agreement with the real world.

$$
T_{p a v}=-5.374-0.752 T_{\text {sur }}+0.022 T_{\text {sur }}^{2}+2.016 T_{\text {avg }}-0.032 T_{\text {sur }} * T_{\text {avg }}+1.549 t_{d}-0.022 \mathrm{D}
$$


Ariawan et al. (2015) also developed a linear regression temperature model for tropical climates experiencing dry and wet seasons, as opposed to winter and summer. Due to the change in seasons, the pavement temperature depends on the air temperature $(\mathrm{T})$ and humidity $(\mathrm{H})$. Separate equations were developed for different pavement depths, for example the model for $70 \mathrm{~mm}$ below the surface is at Equation 5 .

$$
T_{70 \mathrm{~mm}}=1.965+0.755 T_{\text {air }}+0.331 T_{\text {surface }}
$$

For this research, the temperature model developed by Islam et al. (2015) was used. The model is based on the solar radiation and daily temperature data and includes two formulae, one for predicting the minimum temperature (night time) and one for the maximum temperature (day time). For the minimum temperature, the only independent variables are the depth at which the temperature is predicted and the daily minimum temperature (Equation 6). The maximum temperature is also dependent on the intensity of solar radiation (Equation 8). The models were validated by comparing the predicted temperatures to measured pavement temperatures during various prevailing weather conditions (Islam et al. 2015).

$$
y_{\text {min }}=1.84+x_{\min }+20 x
$$

Where: $\mathrm{y}_{\min }=$ predicted daily minimum temperature at any depth $\left({ }^{\circ} \mathrm{C}\right)$.

$\mathrm{x}_{\min }=$ daily minimum surface temperature $\left({ }^{\circ} \mathrm{C}\right)$ as per (Equation 7$)$.

$\mathrm{x}=\operatorname{depth}(\mathrm{m})$.

$$
x_{\min }=1.33 \alpha_{\min }+3.21
$$

Where: $\mathrm{x}_{\min }=$ daily minimum surface temperature $\left({ }^{\circ} \mathrm{C}\right)$.

$\alpha_{\min }=$ daily minimum air temperature $\left({ }^{\circ} \mathrm{C}\right)$.

$$
y_{\text {max }}=2.5+2.91 x_{\max }-25.6 x-0.004 S_{\max }
$$

Where: $\mathrm{y}_{\max }=$ predicted daily maximum temperature at any depth $\left({ }^{\circ} \mathrm{C}\right)$.

$\mathrm{x}_{\max }=$ daily maximum surface temperature $\left({ }^{\circ} \mathrm{C}\right)$ as per (Equation 9$)$.

$\mathrm{x}=\operatorname{depth}(\mathrm{m})$.

$\mathrm{S}_{\max }=$ daily maximum solar radiation $\left(\mathrm{W} / \mathrm{m}^{2}\right)$.

$$
x_{\max }=1.33 \alpha_{\max }+3.21
$$

Where: $\mathrm{x}_{\max }=$ daily maximum surface temperature $\left({ }^{\circ} \mathrm{C}\right)$.

$\mathrm{a} \alpha_{\max }=$ daily maximum air temperature $\left({ }^{\circ} \mathrm{C}\right)$.

The predicted temperatures during summer, autumn, winter and spring days and nights in the Sunshine Coast region (Queensland, Australia) are shown in Figure 1. The daily temperature and solar radiation values used for these predictions were sourced from the Bureau of Meteorology. The reversal of the temperature profiles from day to night is clear. This reflects the exposure of the surface to solar radiation and the prevailing air temperature as well as the insulation provider deeper in the pavement. Consequently, the difference between the minimum and maximum temperatures is much greater near the pavement surface than the difference predicted deeper in the pavement. 


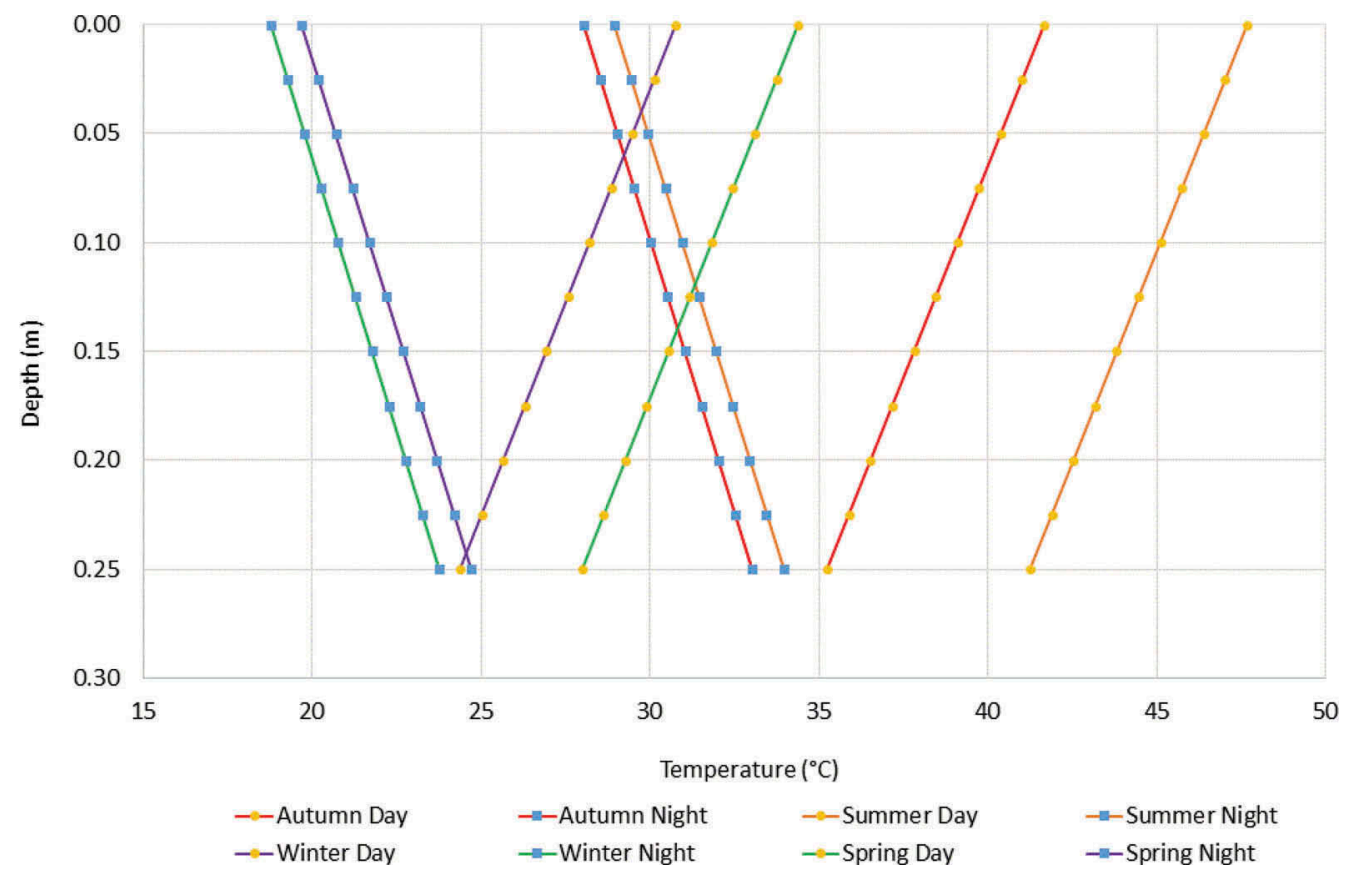

Figure 1. Comparative temperatures predicted by Islam et al. (2015).

\section{METHODS AND RESULTS}

\subsection{Methods}

The effect of using a dynamic modulus in aircraft pavement design was determined by designing a range of pavements based on the standard static asphalt modulus values and then calculating the change in CDF when the pavement thickness was retained, but the asphalt modulus was changed to a dynamic value. To investigate trends across a range of realistic design scenarios, different pavement structures, subgrade conditions and aircraft were considered. Three pavement structures were analysed, intended to be representative of pavements used in the USA (standard pavement with asphalt base course), in Australia (thin asphalt on a granular base) and in France (full depth asphalt), as shown in Figure 2. Each pavement was analysed for four subgrade conditions, intended to be representative of the full range of subgrade conditions encountered in most practical design scenarios (Table 1). All pavements were designed to separately accommodate 100,00 total passes of the B737-800, and A330-300 and B777300ER aircraft at their maximum mass and standard tyre pressure, intended to be representative of typical two, four and six wheeled aircraft.

Table 1. Subgrade conditions.

\begin{tabular}{lll}
\hline CBR $(\%)$ & Modulus $(\mathrm{MPa})$ & Representative of \\
\hline 3 & 30 & Reactive clay or silt \\
6 & 60 & Stiff clay of silt \\
10 & 100 & Gravel \\
15 & 150 & Well compacted sand \\
\hline
\end{tabular}




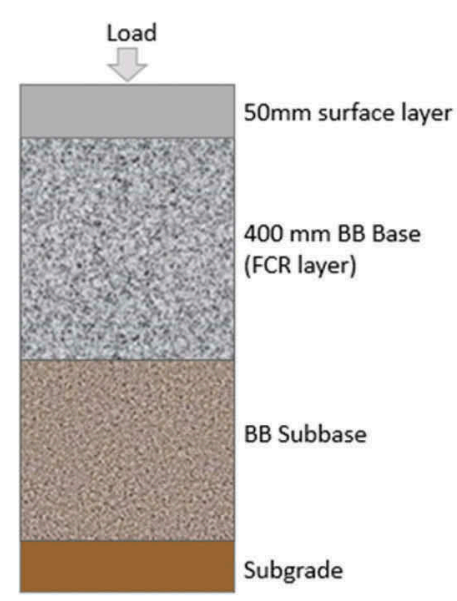

Thin asphalt pavement

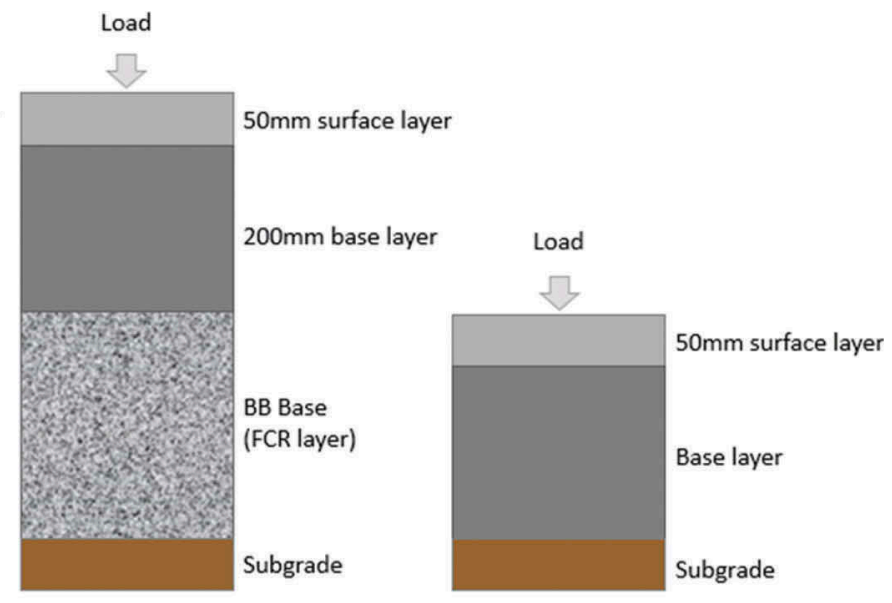

Standard pavement

Full depth asphalt pavement

Figure 2. Pavement structures. Note: BB is Barker \& Brabston sub-layered FCR or subbase, while FCR is fine crushed rock, usually $20 \mathrm{~mm}$ sized.

All asphalt layers were assigned a static modulus of 1,500 $\mathrm{MPa}$ (surface) or 3,300 $\mathrm{MPa}$ (base). The dynamic modulus values were determined from a master curve generated by laboratory testing of a typical airport used for the resurfacing of Rockhampton Airport (Queensland, Australia) in 2018 (Table 2). The asphalt was a nominal $14 \mathrm{~mm}$ sized, densely graded mixture containing a proprietary polymer modified binder and was generally typical of airport asphalt used in Australia (White 2018).

Table 2. Asphalt mixture properties.

\begin{tabular}{lll}
\hline Parameter & Test Method & Value \\
\hline Binder Content (\% by mass) & AS 2891.3.1 & 5.3 \\
Air Voids (\%) & AS 2891.8 & 2.9 \\
Marshall Stability (kN) & AS 2891.5 & 15.6 \\
Marshall Flow (mm) & AS 2891.5 & 2.7 \\
Percentage Passing (by mass) & Australian Standard Sieves (according to AS1141.11.1) \\
\hline Sieve size (mm) & - & Percentage passing (\%) \\
\hline 19.0 & & 100 \\
13.2 & & 97 \\
9.5 & & 82 \\
6.7 & & 70 \\
4.75 & & 58 \\
2.36 & & 45 \\
1.18 & & 33 \\
0.600 & & 13 \\
0.300 & & 8.8 \\
0.150 & & 6.1 \\
0.075 & &
\end{tabular}

The asphalt modulus was measured at all combinations of temperature and load frequency levels detailed in Table 3. The asphalt modulus was measured by repeated flexure of rectangular samples (390 mm wide by $63.5 \mathrm{~mm}$ high) under four point bending, known in Australia as the complex modulus test, as detailed in test method AG:PT/T274. 
Table 3. Asphalt modulus temperature and load frequency levels.

\begin{tabular}{ll}
\hline Temperature $\left({ }^{\circ} \mathrm{C}\right)$ & Load frequency $(\mathrm{Hz})$ \\
\hline 5 & 0.1 \\
15 & 0.2 \\
25 & 0.5 \\
30 & 1 \\
40 & 2 \\
& 5 \\
& 10 \\
& 20 \\
\hline
\end{tabular}

\subsection{Results}

The laboratory test results (Figure 3 ) were used to develop a master curve of asphalt modulus, allowing the determination of modulus values at any temperature and load speed/frequency combination. The master curve was generated with reduced frequency as the independent variable (Figure 4) but an equivalent master curve with reduced temperature as the independent variable is equally valid, because the two parameters (temperature and frequency) are combined into the single reduced frequency (or reduced temperature) (Austroads 2013).

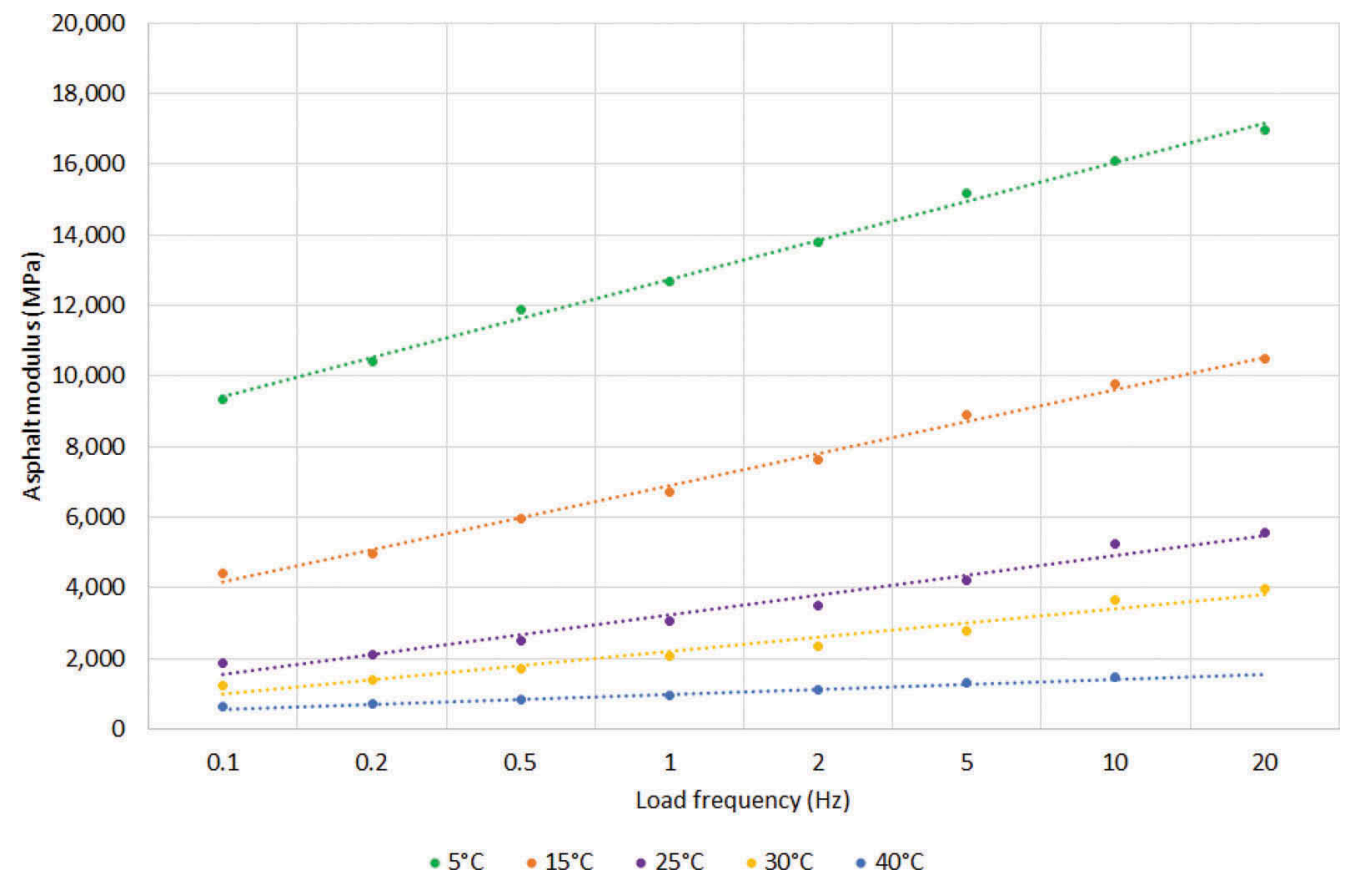

Figure 3. Modulus results at various test temperatures and frequencies. 


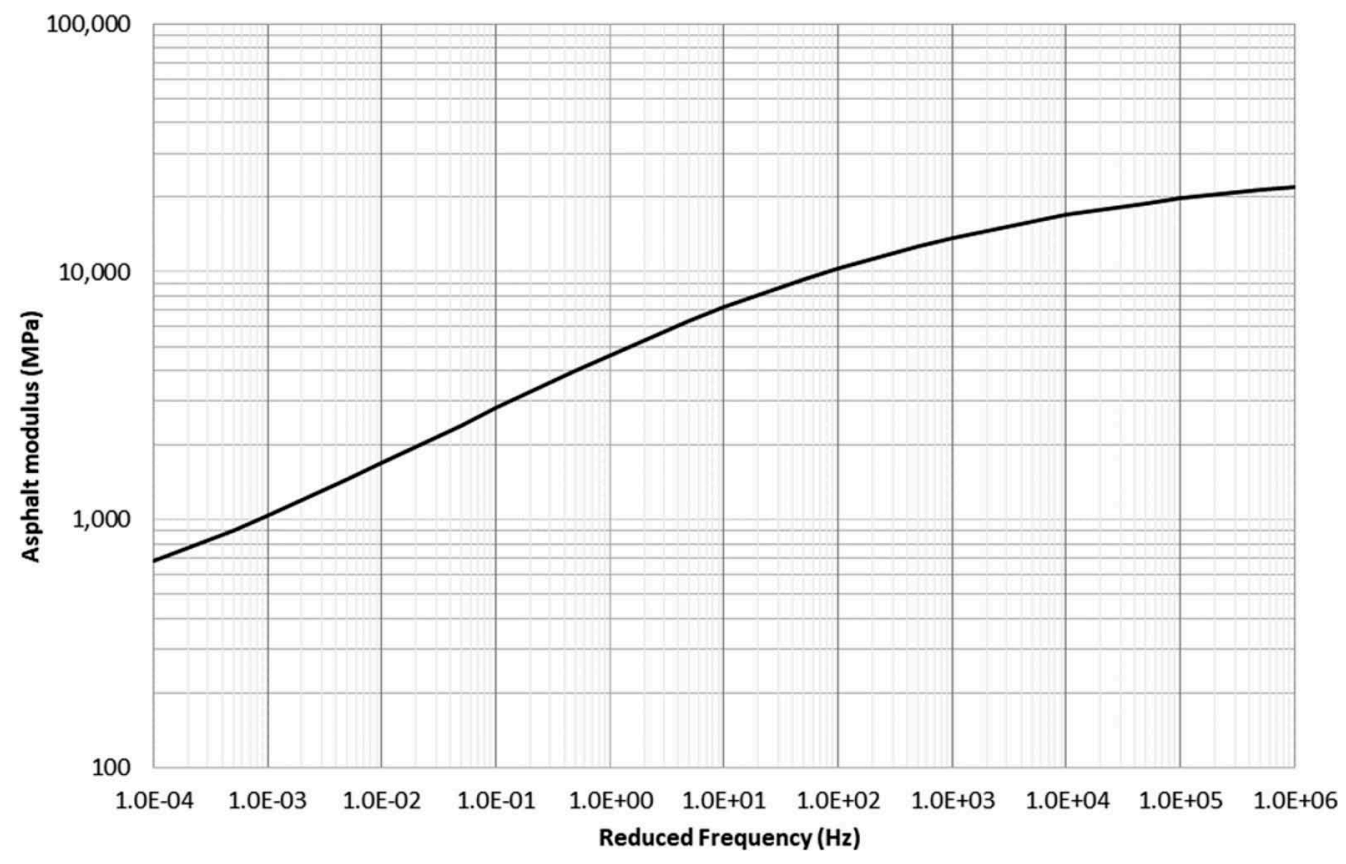

Figure 4. Master curve developed from asphalt modulus results.

As discussed previously, the traditional static asphalt modulus values were used to calculate the required thicknesses of the pavement layer above the subgrade for all pavement types, subgrades and aircraft combinations (Table 4). These are subsequently referred to as the reference thicknesses.

Table 4. Total pavement thickness of pavements ( $\mathrm{mm})$.

\begin{tabular}{lllll}
\hline Pavement type & Subgrade & B737-800 & A330-300 & B777-300ER \\
\hline Thin asphalt pavement & CBR 3 & 1,369 & 1,907 & 2,580 \\
& CBR 6 & 951 & 1,098 & 1,550 \\
& CBR 10 & 674 & 776 & 848 \\
Standard pavement & CBR 15 & 506 & 593 & 603 \\
& CBR 3 & 1,084 & 1,410 & 1,869 \\
& CBR 6 & 762 & 904 & 1,190 \\
Full depth asphalt & CBR 10 & 528 & 628 & 707 \\
& CBR 15 & 340 & 445 & 454 \\
& CBR 3 & 493 & 654 & 856 \\
& CBR 6 & 399 & 477 & 595 \\
& CBR 10 & 333 & 380 & 422 \\
\hline
\end{tabular}

\section{DISCUSSION}

The full depth asphalt required the thinnest thickness, whereas the thin asphalt pavement had the greatest thickness for any subgrade and aircraft combination. All pavement types required a greater thickness when for a lower subgrade CBR value and the larger aircraft required thicker pavements. These trends are well established and are not considered further. 


\subsection{Effect of asphalt sub-layers}

Because the introduction of variable asphalt modulus values with depth requires many sublayers to be generated, it was first necessary to determine the influence of sub-layering the asphalt within the APSDS pavement model. Nine pavement-subgrade-aircraft combinations were modelled with $25 \mathrm{~mm}$ sub-layers, with each sub-layer assigned the static modulus value (1,500 MPa or 3,300 MPa) used to determine the reference thicknesses (Table 4). The CDF with sub-layering was calculated for each reference thickness and compared to the CDF of the same combinations modelled as single layers. The selected pavement-subgrade-aircraft combinations and CDFs are summarised in Table 5.

Table 5. Comparison of single layer and sub-layered CDF values for reference thicknesses.

\begin{tabular}{lllllll}
\hline & \multicolumn{2}{l}{ CDF using single layers } & \multicolumn{3}{l}{ CDF using sub-layers } \\
\cline { 2 - 7 } Pavement type and subgrade & B737 & A330 & B777 & B737 & A330 & B777 \\
\hline Standard pavement CBR 3 & 1.000 & 1.000 & 1.000 & 1.000 & 1.000 & 1.000 \\
Thin asphalt pavement CBR 6 & 1.000 & 1.000 & 1.000 & 1.000 & 1.000 & 1.000 \\
Full depth asphalt pavement CBR 10 & 0.998 & 0.996 & 0.999 & 0.998 & 0.997 & 0.999 \\
\hline
\end{tabular}

All CDF values associated with sub-layering were within $0.5 \%$ of the reference thickness CDF values. The slight deviations from exact agreement reflects the precision to which APSDS adjusts a pavement thickness to achieve a CDF of 1.0, and are of no practical consequence. It was concluded that the addition of sub-layers and interfaces did not introduce any change in the pavement modelling. Consequently, the effect of dynamic modulus on the pavement structures could be determined by comparing the pavement structures with sub-layered asphalt courses directly to the reference pavement thicknesses in Table 4.

\subsection{Effect of aircraft speed on asphalt modulus}

The modulus of the asphalt increased with test frequency (Figure 3) and consequently the master curve shows that dynamic modulus increased with aircraft speed. For example, at $25^{\circ} \mathrm{C}$ the modulus ranges from $3,250 \mathrm{MPa}$ at $1 \mathrm{~km} / \mathrm{hr}$, up to $9,410 \mathrm{MPa}$ at $300 \mathrm{~km} / \mathrm{hr}$ (Figure 5). This indicates that pavements of equal thickness will have less structural strength in parking areas, where aircraft move slowly, than on taxiways, where $40 \mathrm{~km} / \mathrm{hr}$ is a common speed, or for runways, where aircraft land at around $250 \mathrm{~km} / \mathrm{hr}$. This difference in modulus has significant implications for pavement thickness and/or predicted life when using dynamic modulus in pavement design.

\subsection{Effect of temperature on asphalt modulus}

Temperature also has a significant effect on asphalt modulus and this is reflected in the test results (Figure 3). Figure 6 shows the asphalt modulus at various temperatures, compared to the modulus at $25^{\circ} \mathrm{C}$, which is a common reference temperature for asphalt modulus values. On average, the modulus at $5^{\circ} \mathrm{C}$ was $256 \%$ greater than at $25^{\circ} \mathrm{C}$, while at $40^{\circ} \mathrm{C}$, the average modulus was just $30 \%$ of the $25^{\circ} \mathrm{C}$ modulus values. That is, that modulus approximately doubles with every $4^{\circ} \mathrm{C}$ decrease in temperature. Since the temperature at the surface of the pavement is expected to differ from the temperature $250 \mathrm{~mm}$ below the surface by more than $5^{\circ} \mathrm{C}$, the effect on pavement thickness and/or predicted life is expected to be significant. 


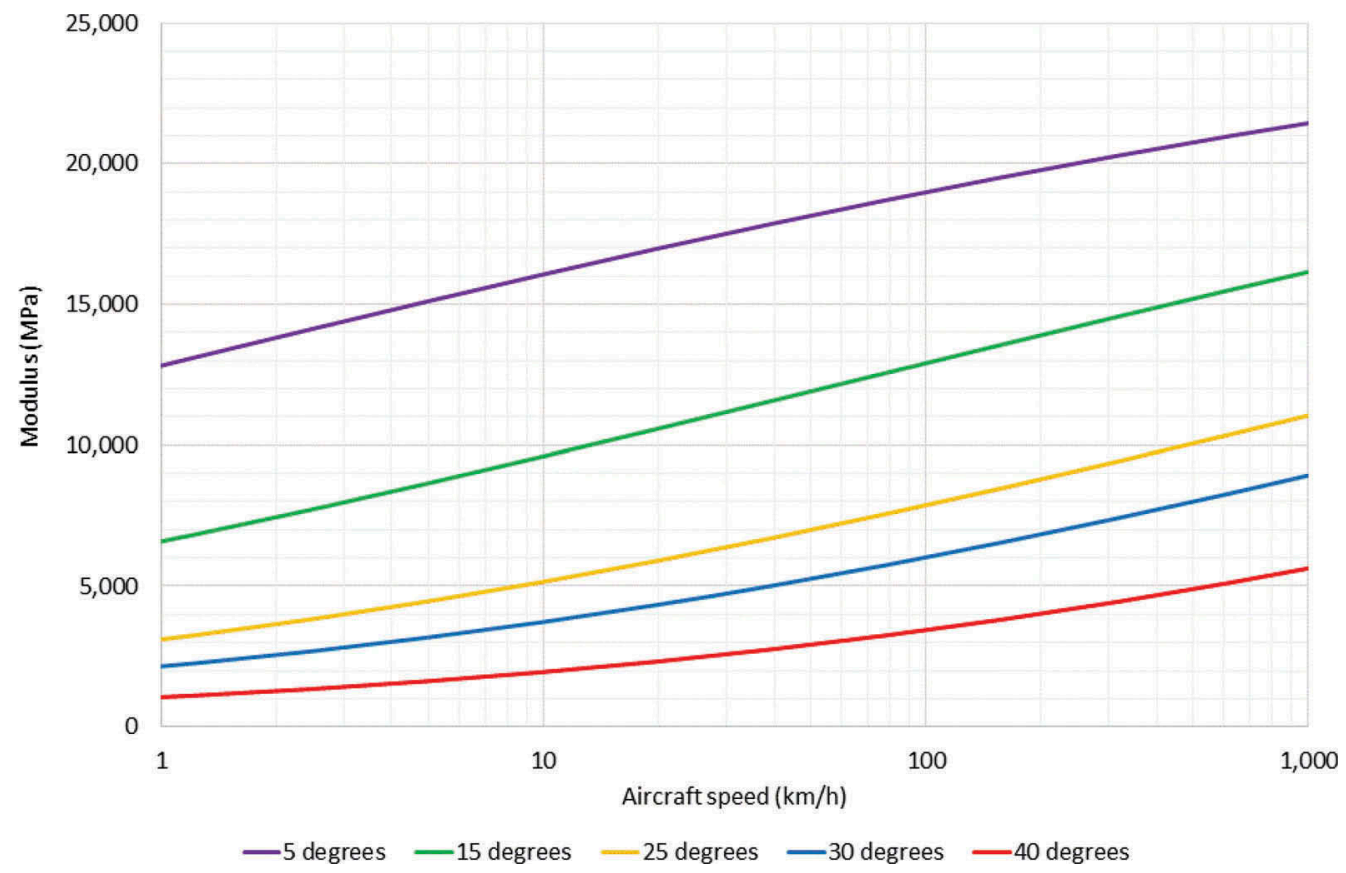

Figure 5. Effect of aircraft speed on asphalt modulus.

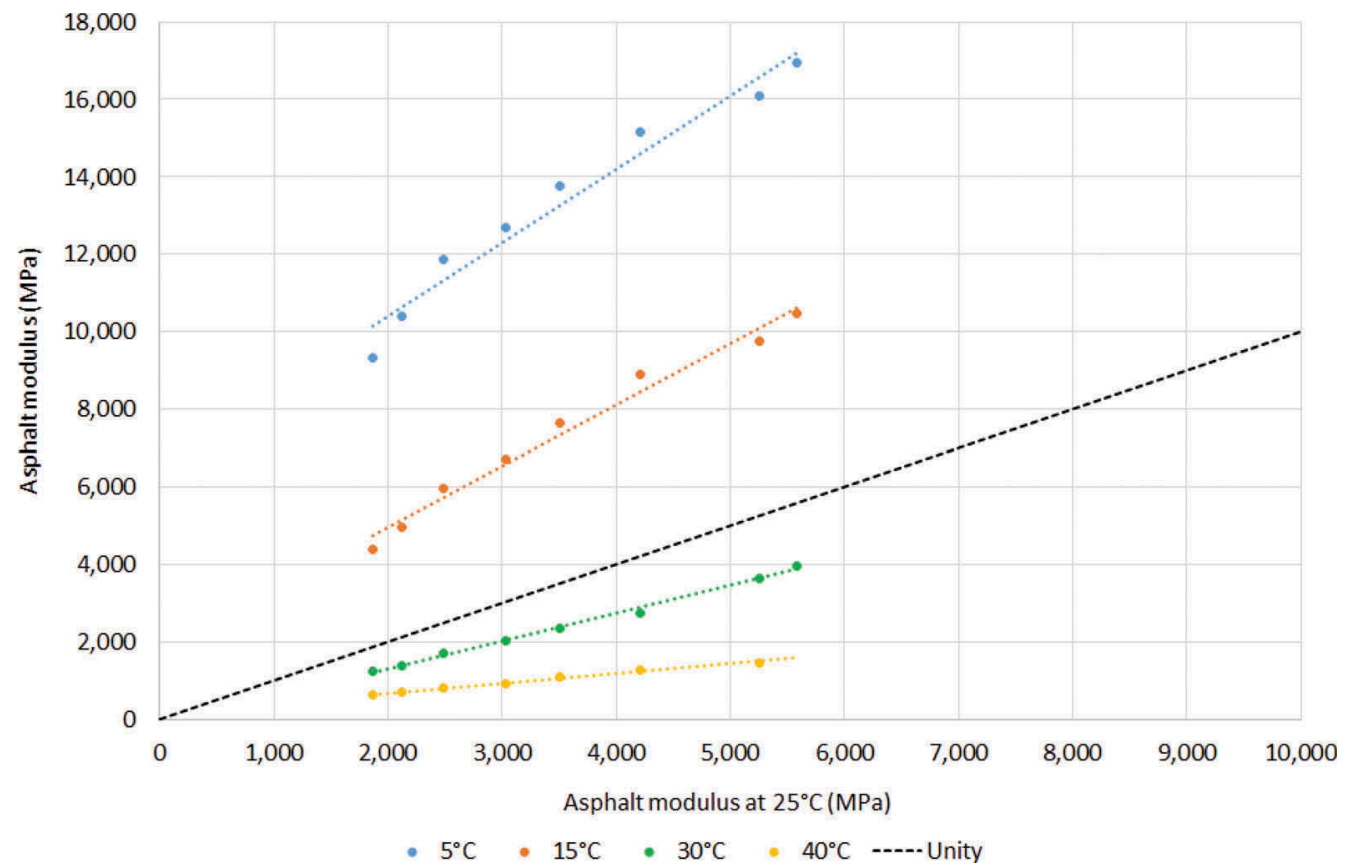

Figure 6. Effect of temperature on asphalt modulus. 


\subsection{Effect of dynamic modulus on pavement}

The CDF value associated with dynamic asphalt modulus was calculated for the reference pavement thickness, for every combination of pavement type, aircraft and sub-grade CBR. The dynamic modulus values were determined from the modulus master curve (Figure 4) based on the $25 \mathrm{~mm}$ thick sub-layers, for each of the four temperature with depths models shown in Figure 3. The CDFs are shown in Figure 7. The difference in the seasons is clear. On average the summer CDF values are approximately 918,000 times higher than the corresponding winter CDF values. The range of CDF ratios was 1.1 to $13,000,000$. The broad range of summer to winter CDF ratios also highlights the difference in trends for the three pavement types.

CDF value summary statistics are in Table 6. The thin asphalt pavement was associated with only moderate differences in CDF, indicating that the incorporation of dynamic modulus had only modest influence on the predicted pavement lives. This reflects the relatively low portion of asphalt $(50 \mathrm{~mm})$ in the overall pavement composition $(506 \mathrm{~mm}$ to $2,580 \mathrm{~mm})$. In contrast, the full depth asphalt pavement, which is comprised entirely of asphalt, was very sensitive to the inclusion of dynamic modulus, with an average CDF of 0.91 , but a range of CDF values of 0.00014 to 65,500 . This indicates that based on day time summer temperature profiles, the pavement would fail after just $0.0015 \%$ of the design traffic, which is 11 days of a 20 year design life. However, under night time temperature conditions in winter, the 20 year design life would be extended to over 140,000 years. The standard (FAA) type of pavement, with $250 \mathrm{~mm}$ of asphalt, was part-way in between, with CDF values of 0.00023 to 5,440.

Overall, the thicker the asphalt layer, the greater the temperature and modulus variation and the greater the effect on the predicted pavement life. Following the same trend, the temperature at which the CDF using the dynamic modulus method was equal to that for the static modulus values, was constant for each load and subgrade strength combination of the thin asphalt pavement, but varied for pavements with thicker asphalt layers. The fixed modulus modelling method overestimated the thin asphalt pavement's strength up to an outside maximum temperature of $30^{\circ} \mathrm{C}$. For temperatures above $30^{\circ} \mathrm{C}$, the traditional static modulus approach overestimated the strength of thin asphalt pavements, compared to the dynamic modulus approach. This could result in pavement failures on extremely hot summer days. For the standard (FAA) pavement, the temperature at which dynamic modulus CDF values were equal to 1.0 , ranged modestly from $25.5^{\circ} \mathrm{C}$ to $26.1^{\circ} \mathrm{C}$, depending on the aircraft and subgrade combination. For the full depth asphalt pavement, the temperature of parity ranged even more, from $25.8^{\circ} \mathrm{C}$ to $32.4^{\circ} \mathrm{C}$. This indicated that introducing dynamic modulus to pavement design becomes more complex as the asphalt depth increases, due to the dependence of the asphalt modulus on the asphalt temperature.

Further complicating the issue, this analysis has only considered the asphalt modulus as a function of asphalt temperature, with a constant aircraft speed of $10 \mathrm{~km} / \mathrm{hr}$ adopted. However, to introduce dynamic modulus to routine pavement thickness design, the effect of loading speed must also be considered, with asphalt modulus values generally higher for runways than for taxiways and parking aprons. However, aircraft also line-up on runway as they await take-off clearance and in many regional airports, aircraft perform u-turns at the runways ends before taxiing back up the runway to the exit taxiway. Consequently, even the loading speed on a typical runway varies greatly, from stationary to landing speed. Similar complexity exists in highway pavements, which might be posted as a $100 \mathrm{~km} / \mathrm{hr}$ speed zone, but may regularly have stationary truck traffic during peak hour congestion.

\section{CONCLUSION}

It was concluded that the thicker asphalt layers within a pavement caused greater temperature and modulus sensitivity through the pavement profile. This occurred because a greater portion of the pavement profile was temperature dependent. The fixed modulus method is therefore more appropriate to model thin asphalt pavements than full depth asphalt pavements, as it 


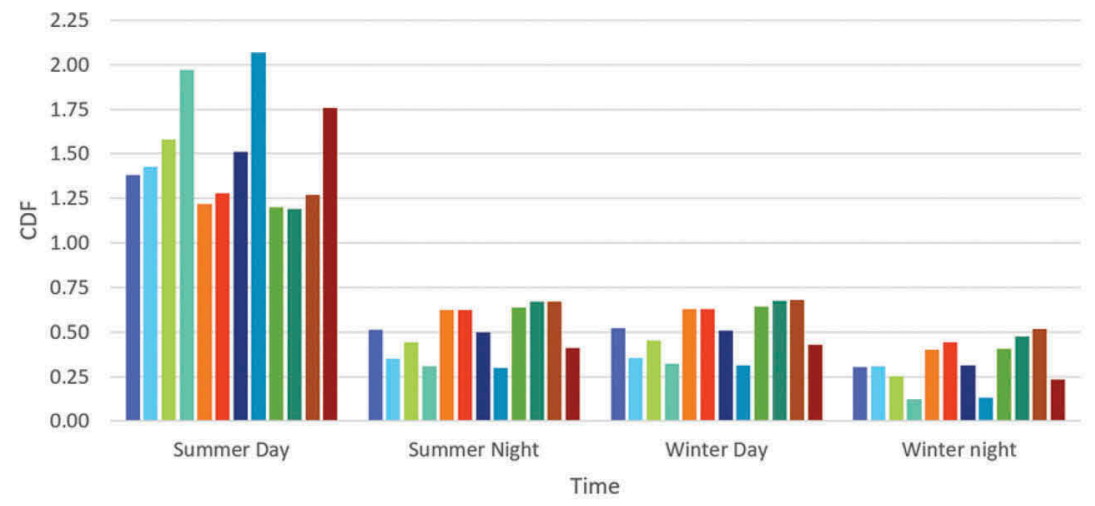

=B737-CBR $3=\mathrm{B} 737-\mathrm{CBR} 6=\mathrm{B} 737-\mathrm{CBR} 10=\mathrm{B} 737-\mathrm{CBR} 15=\mathrm{A} 330-\mathrm{CBR} 3=\mathrm{A} 330-\mathrm{CBR} 6$

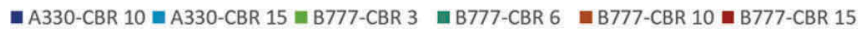

(a) Thin asphalt pavement

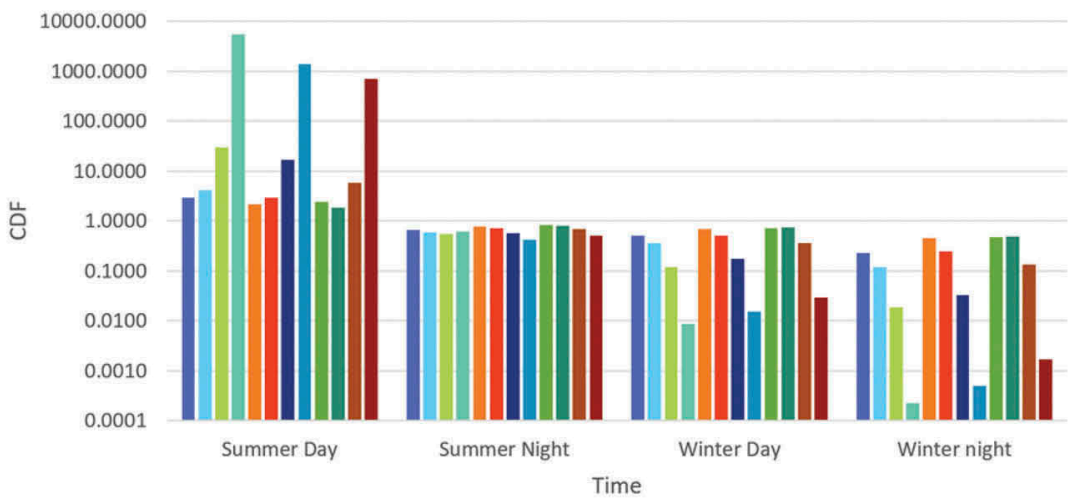

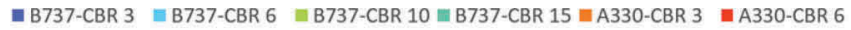

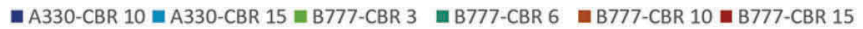

(b) Standard (FAA) pavement

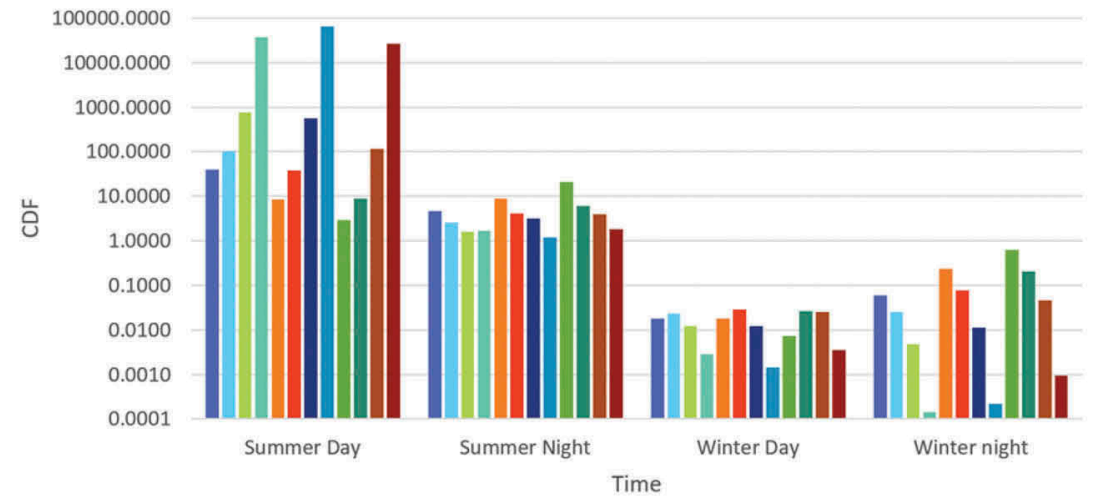

=B737-CBR $3=\mathrm{B} 737-\mathrm{CBR} 6=\mathrm{B} 737-\mathrm{CBR} 10=\mathrm{B} 737-\mathrm{CBR} 15=\mathrm{A} 330-\mathrm{CBR} 3 \approx \mathrm{A} 330-\mathrm{CBR} 6$

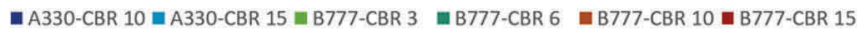

\section{(c) Full depth asphalt pavement}

Figure 7. CDF of reference pavement for dynamic modulus in different seasons. 
Table 6. Summary statistics of reference pavement CDF values.

\begin{tabular}{llll}
\hline Statistic & Thin asphalt & Standard $($ FAA $)$ & Full depth asphalt \\
\hline Minimum & 0.12 & 0.00023 & 0.00014 \\
Medium & 0.52 & 0.55 & 0.91 \\
Maximum & 2.07 & 5,440 & 65,500 \\
\hline
\end{tabular}

does not account for large modulus variations. For pavements with a thicker asphalt layer, the dynamic modulus method was more precise and may be more representative of field conditions. It was also concluded that the difference in modulus associated with summer and winter, or day and night, temperature profiles changes the predicted life of the pavement by orders of magnitude, suggesting that all significant pavement damage occurs on the hottest few days of the pavement's life. This research demonstrated that dynamic modulus can relatively efficiently be incorporated into aircraft pavement design. However, many challenges remain, including the analysis of the traffic volumes that occur during various representative temperature conditions and how to cumulatively account for the low damage that occurs in colder weather, as well as the excessive damage predicted to occur during hot weather. In light of the fact that very few aircraft pavement failures are attributed to inadequate pavement thickness, the introduction of dynamic modulus to routine aircraft pavement thickness design is unlikely to be justifiable and is expected to introduce more challenges than it is expected to solve.

\section{REFERENCES}

AAA 2017, Airfield Pavement Essentials, Airport Practice Note 12, Australian Airports Association, Canberra, Australia, April.

Ariawan, IMA, Subagio, BS \& Setiadji, BH 2015, 'Development of asphalt pavement temperature model for tropical climate conditions in West Bali region', Procedia Engineering, Vol 125, pp.474-480.

Austroads 2013, Improved Design Procedures for Asphalt Pavements: Pavement Temperature and Load Frequency Estimation, AP-T248-13, 27 September.

Austroads 2016, Characterisation of Flexural Stiffness and Fatigue Performance of Bituminous Mixes, accessed 26 April $2020<$ https://austroads.com.au/publications/pavement/agpt-t274-16>.

Balay, JM, Caron, C \& Lerat, P 2009, 'Alize-Lcpc Airfield pavement, a new software for the rational design of airport pavement', $2^{\text {nd }}$ European Airport Pavement Workshop, Athens, Greece, 13-14 May.

Barker, WR \& Brabston, WN 1975, Development of a Structural Design Procedure for Flexible Aircraft Pavements, Report No S77-17, US Army Corps of Engineers, Waterways Experiment Station, Vicksburg, USA.

FAA 2016, Advisory Circular 150/5320-6F, accessed 10 May 2019 http://www.faa.gov/documentlibrary/ media/advisory_circular/150-5320-6f.pdf.

FAA 2017, FAARFIELD, Version 1.42, Federal Aviation Administration, Washington, District of Columbia, USA, 18 September, accessed 17 December $2017<$ http://www.airporttech.tc.faa.gov/Down load/Airport-Pavement-Software-Programs/Airport-Software-Detail/ArtMID/3708/ArticleID/4/ FAARFIELD-142>.

Gedafa, DS, Hossain, M \& Romanoschi, SA 2014, 'Perpetual pavement temperature prediction model', Road Materials and Pavement Design, Vol. 15, 1, pp. 55-65, DOI:10.1080/14680629.2013.852610.

Gray, C, Yeaman, J \& Tighe, S 2015, 'Using innovative in-situ measuring tools to better understand asphalt performance', AAPA International Flexible Pavements Conference, Gold Coast, Queensland, Australia, 13-16 September.

Huang, YH 1993, Pavement Analysis and Design, Prentice-Hall, New Jersey, USA.

Islam, MR, Ahsan, S and Tarefder, RA 2015, 'Modeling temperature profile of hot-mix asphalt in flexible pavement', International Journal of Pavement Research and Technology, vol. 8, no. 1, pp. 47-52, doi: 10.6135/ijprt.org.tw/2015.8(1).47.

Mincad 2010, APSDS5: Airport Pavement Structural Design System: User Manual, Revision 5.0.055, 9 November, accessed 30 November 2017, <https://www.mincad.com.au/downloads/access/? download>. 
Mounier, D, Broutin, M and Bost, R 2015, 'Mechanistic-Empirical Procedure for Flexible Airfield Pavement Design: The New French Technical Guidance', Airfield and Highway Pavements, pp. 720-729. Doi: $10.1061 / 9780784479216.064$.

Pan, T, Tutumluer, E \& Carpenter, SH 2005, 'Effect of coarse aggregate morphology on the resilient modulus of hot-mix asphalt', Transportation Research Record, no. 1929, pp. 1-9.

TMR 2017, A New Approach to Asphalt Pavement Design, accessed 26 April 2020, <https://www.tmr.qld. gov.au/-/media/busind/techstdpubs/Technical-notes/Pavements-materials-geotechnical/TN167.pdf>.

Wardle, LJ, 1977, Program CIRCLY User's Manual, Commonwealth Scientific and Industrial Research Organisation, Australia, Division of Applied, Geomechanics, Geomechanics Computer Program No 2.

Wardle, L \& Rodway, B 1998, 'Recent developments in flexible aircraft pavement design using the layered elastic method', $3^{\text {rd }}$ International Conference on Road and Airfield Pavement Technology, Beijing, April.

White, G 2018, 'State of the Art: Asphalt for Airport Pavement Surfacing', International Journal of Pavement Research and Technology, vol. 11, no. 1, pp. 77-98.

White, G \& Embleton, K 2015, 'Next generation binder for airport asphalt', $16^{\text {th }}$ AAPA International Flexible Pavement Conference, Gold Coast, Queensland, Australia, 13-16 September.

White, G, Kelly, G, Fairweather, H \& Jamshidi, A 2020, 'Theoretical socio-enviro-financial cost analysis of equivalent flexible aircraft pavement structures', $99^{\text {th }}$ Annual Meeting of the Transportation Research Board, Washington, District of Columbia, USA, 12-16 January. 